\title{
THE IDENTITY OF CHAETOCLUSIA AFFINIS JOHNSON AND ITS PLACEMENT IN SOBAROCEPHALA CZERNY (DIPTERA: CLUSIIDAE)*
}

\author{
By Norman E. Woodley \\ Systematic Entomology Laboratory, IIBIII, ARS, USDA \\ c/o U. S. National Museum of Natural History \\ Washington, DC 20560
}

Johnson (1913) described Chaetoclusia affinis on the basis of one male and one female from New Jersey. His brief and inadequate description has not allowed subsequent authors to recognize the species and omits discussion of characters later used to define clusiid genera. Melander and Argo (1924) simply repeated Johnson's description and mentioned that they had not seen his material.

I have recently examined the holotype male and allotype female of $C$. affinis, which are housed in the Museum of Comparative Zoology at Harvard University (MCZ \#7873). It was readily apparent that Johnson had placed the species in the wrong genus, and that $C$. affinis actually belongs in the genus Sobarocephala Czerny, not Chaetoclusia Coquillett. Both of Johnson's specimens lack the longer, bristle-like hairs on wing vein $R_{1}$, which are characteristic of Chaetoclusia. Johnson probably placed the species in Chaetoclusia because of its densely pubescent antennal arista, a character state found in Chaetoclusia bakeri Coquillett, the type species of the genus. This feature, however, is not unique to Chaetoclusia, and in fact partially defines the "plumata" species group of Sobarocephala, as recognized by Soós (1963).

When $S$. affinis is run through the most recent key to Nearctic Sobarocephala (Sabrosky and Steyskal, 1974), it runs without difficulty to $S$. testacea Soós. The holotype male of $S$. testacea, housed in the U. S. National Museum of Natural History, was recently examined and found to be conspecific with $S$. affinis. Johnson's allotype is probably also conspecific, but there is difficulty in separating females of this species from those of $S$. muesebecki Sabrosky and Steyskal. The latter species is known with

*Manuscript received by the editor February 15, 1984. 
certainty from Florida, and from a questionable specimen from Maryland (see Sabrosky and Steyskal, 1974: 378).

As a result of this study, the following nomenclatural changes result:

Sobarocephala affinis (Johnson), 1913: 101. NEW COMBINATION.

Sobarocephala testacea Soós, 1964: 449. NEW SYNONYMY.

The holotype of Chaetoclusia affinis Johnson is in poor condition. It is missing the head and the legs beyond the trochanters, except that the right front femur and tibia are present. I have removed and cleared most of the abdomen, including the male terminalia, and placed them in glycerin in a microvial on the specimen pin, so that they will be better preserved and more useful for future workers. Due to the absence of the head, the male genitalia are the only features of the type that will allow conclusive identification of the specimen.

Because C. affinis Johnson really belongs in Sobarocephala, this deletes the only species ascribed to Chaetoclusia from the Nearctic fauna. The genus is now known only from the Neotropical Region extending from Nicaragua south to Peru, and also Haiti and St. Vincent (Soós, 1968). It seems unlikely that the genus will be found in the Nearctic Region, although its Caribbean distribution makes it just possible that it might someday be found in southern Florida.

I wish to thank Wayne Mathis, Department of Entomology, Smithsonian Institution, and D. R. Miller, Systematic Entomology Lab, USDA, for reviewing the manuscript.

\section{Literature Cited}

JoHNSON, C. W.

1913. A study of the Clusiodidae, (Heteroneuridae) of the eastern United States. Psyche 20:97-101.

Melander, A. L. and N. G. Argo.

1924. A revision of the two-winged flies of the family Clusiidae. Proc. U. S. Nat. Mus. 64:1-54.

Sabrosky, C. W. and G. C. Steyskal.

1974. The genus Sobarocephala (Diptera: Clusiidae) in America north of Mexico. Ann. Ent. Soc. Amer. 67:371-385.

Soós, Á.

1963. Identification key to the species of the "plumata-group" of the genus Sobarocephala Czerny (Diptera: Clusiidae). Acta Zool. Acad. Sci. Hung. 9:391-396. 
1964. New Sobarocephala-species from the "plumata-group" (Diptera, Clusiidae). Ann. Hist.-nat. Mus. Nat. Hung. 56:449-455.

1968. Family Clusiidae, No. 84. In A catalogue of the Diptera of the Americas south of the United States. São Paulo, Museu de Zoologia, Universidade de São Paulo, 13 pp. 

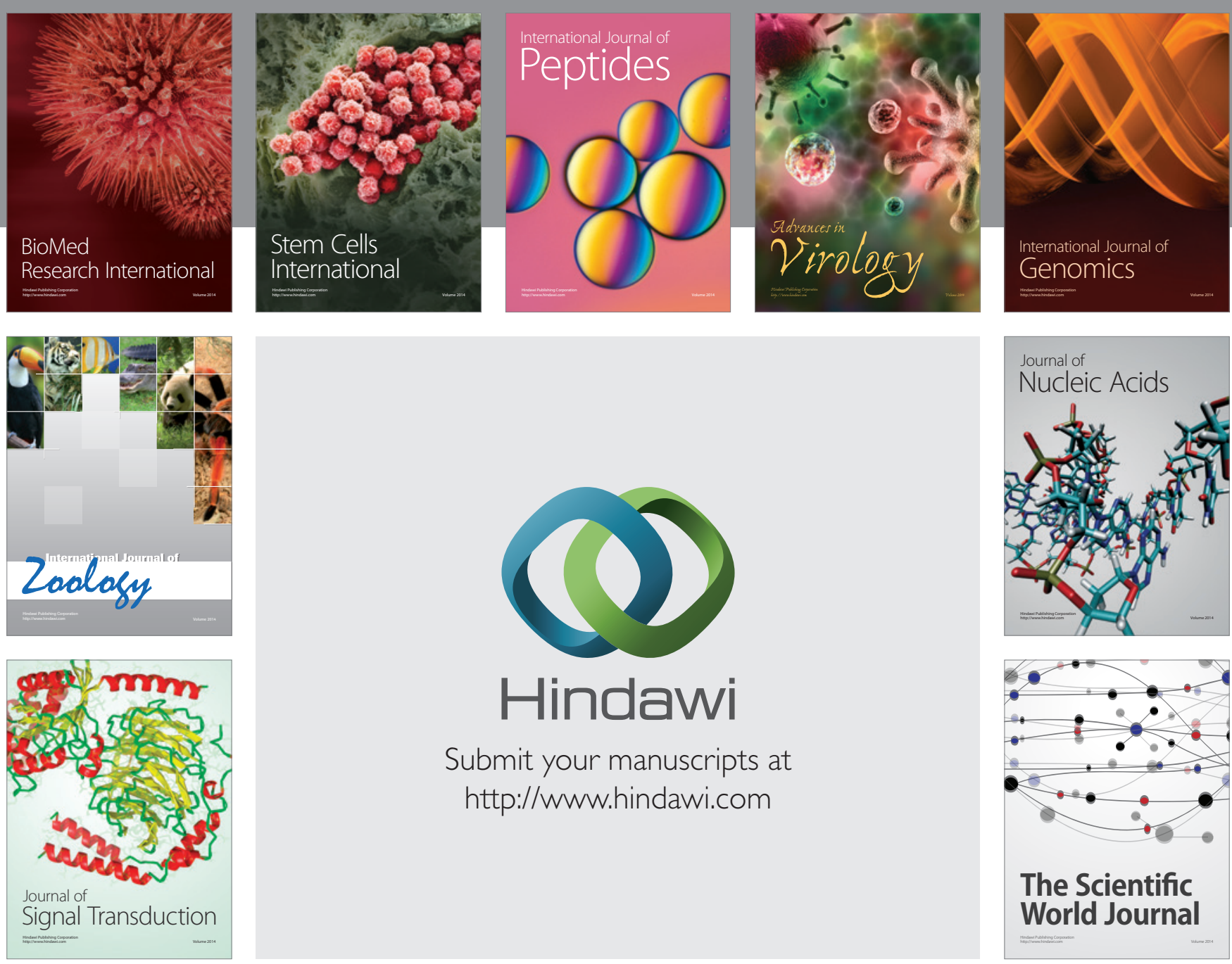

Submit your manuscripts at

http://www.hindawi.com
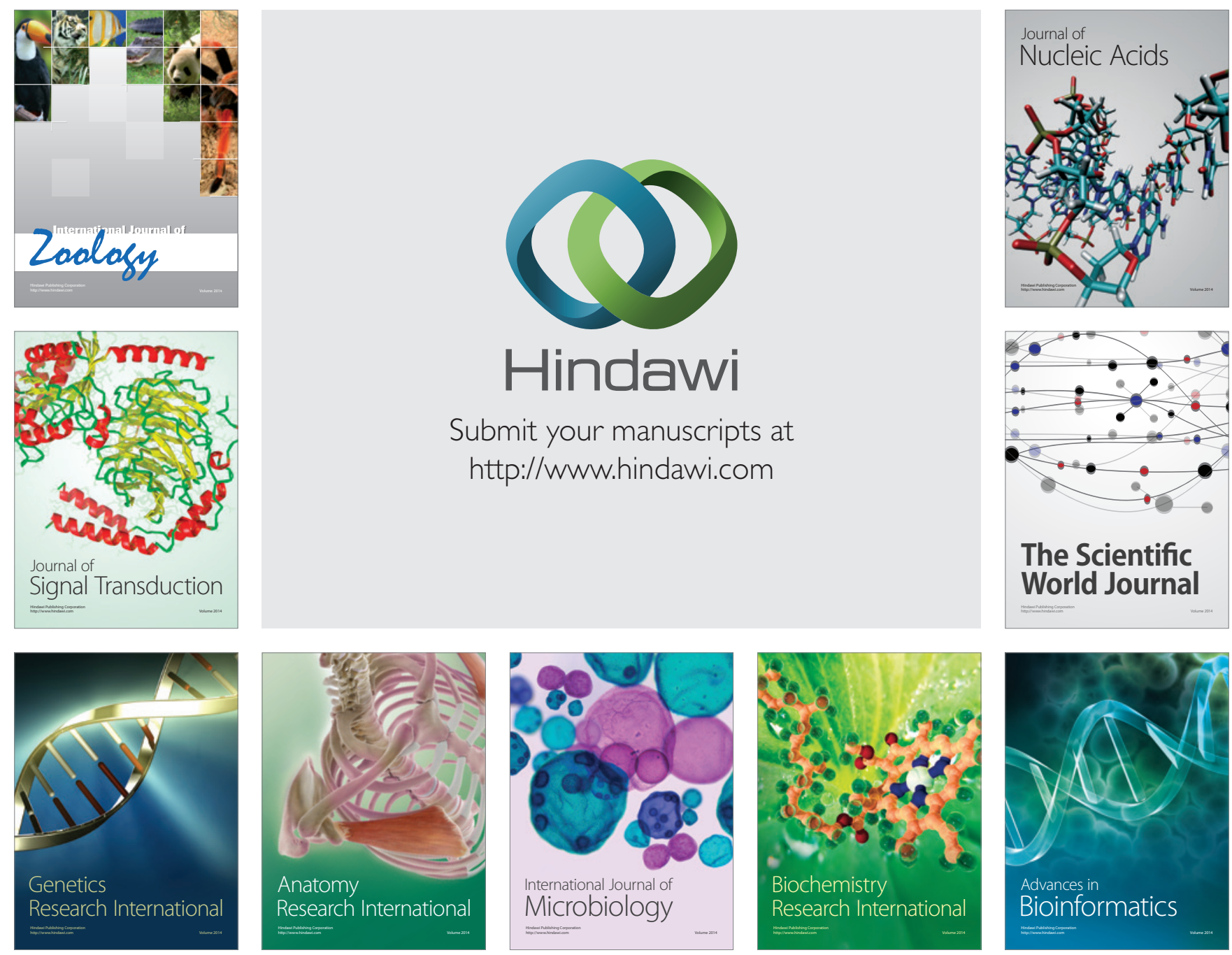

The Scientific World Journal
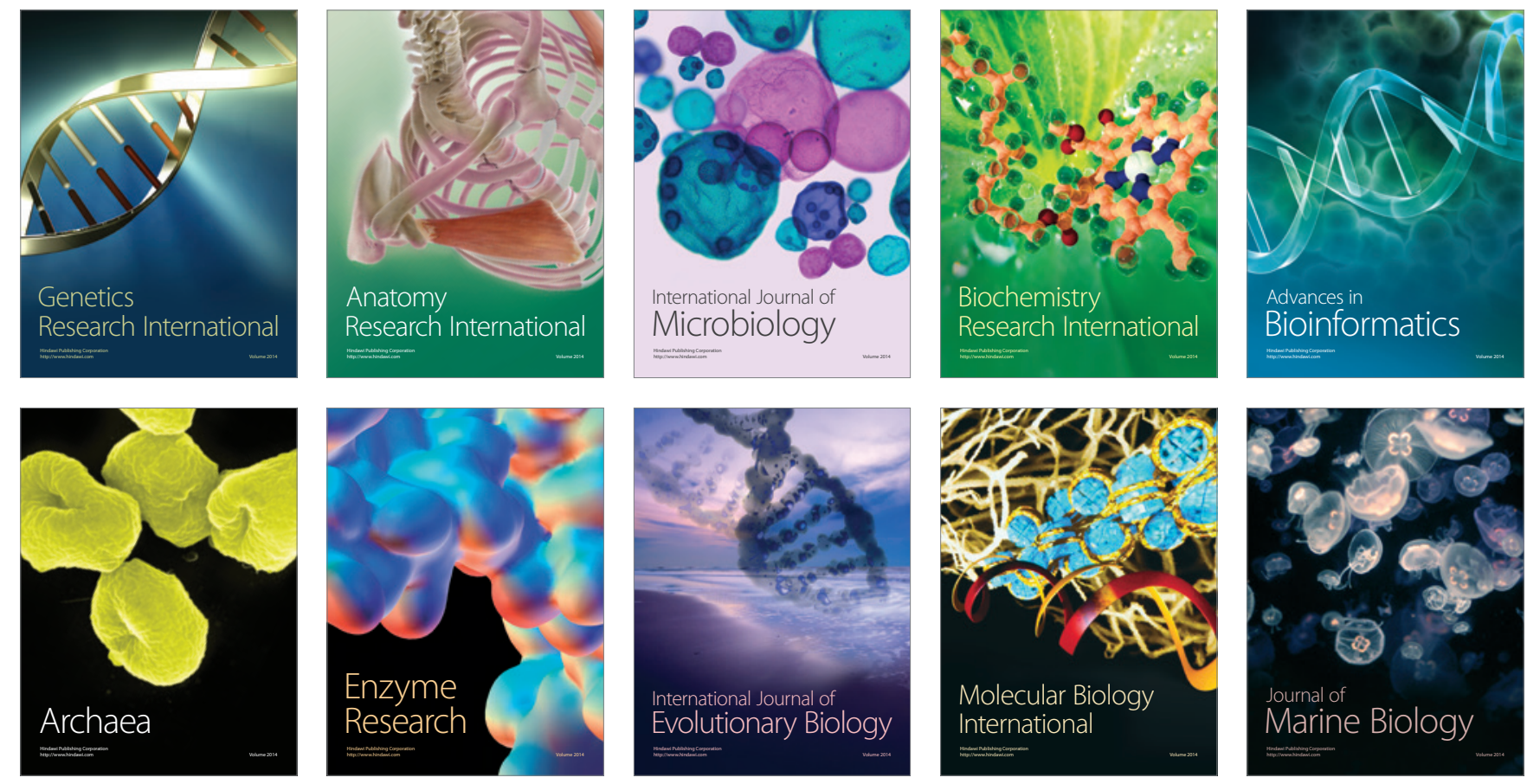